\title{
The effect of surface texturing in the sliding surface on tribological characteristics of alloy steel under wet condition
}

\author{
H. S. Patil, D. C. Patel \\ Mechanical Department, GIDC Degree Engineering College, Abrama, Gujarat, India \\ hspatil28@gmail.com,pateldcp@gmail.com
}

\begin{abstract}
Surface texturing plays an increasingly important role as it can directly influence the tribological behaviors of contact surfaces in many ways. In texturing, tribological performance depends upon the types of design texture used and methods of fabricating texture on the surface. In this research work, friction and wear behaviors of surface textured EN-31 alloy steel have been investigated under wet condition by using DUCOM linear reciprocating tribometer. The textured dimples are fabricated by micro-EDM and micro-drilling CNC machining processes. Initially un-textured surfaces of EN-31 alloy steel with EN-8 steel pin are experimented for friction and wear under ISO-68 and ISO-220 lubricant oil. Under the different normal load conditions, it has been observed that the ISO 68 oil gives better friction-wear characteristics with respect to ISO-220 oil. Then after textured surfaces were investigated by using optimized ISO-68 lubricant. Experimental results on micro-EDM provide better friction and wear properties with respect to micro-drilling CNC. Surface texturing may act as wear debris trapper, lubricant reservoirs, hydrodynamic lift, and retarding the lubricant molecules flow in a particular path where potential exists. In this work, it has observed that texturing by micro-EDM enhanced mixed lubrication and minimum friction in mixed lubrication leads to decrement of wear loss.
\end{abstract}

KEYwORDS. Micro dimples; EN-31 alloy steel; Normal load; Friction and wear.

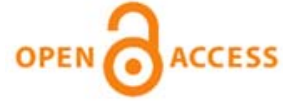

Citation: Patil, H. S., Patel, D. C., The effect of surface texturing in the sliding surface on tribological characteristics of alloy steel under wet condition, Frattura ed Integrità Strutturale 57 (2021) $1-13$.

Received: 20.02 .2021

Accepted: 29.04.2021

Published: 01.07.2021

Copyright: (C) 2021 This is an open access article under the terms of the CC-BY 4.0, which permits unrestricted use, distribution, and reproduction in any medium, provided the original author and source are credited.

\section{INTRODUCTION}

$\mathrm{I}$ $\mathrm{n}$ the recent era surface texturing has become an area of interest for modifying the surface topography of the materials. Surface texturing is the process of modifying the surface to alter its surface features such as surface tension, wettability, and tribological characteristics i.e. friction and wear properties. In recent years, surface texturing which involves flat and smooth lands interrupted by local depressions has been well known in improving the tribological characteristics of the materials [1]. It has also been proved that textured surfaces exhibit good performance from 
boundary lubrication to fluid film lubrication. Many studies have shown the outstanding performance of surface texturing technology in improving tribological properties. To create micro-texturing on the surface many fabrication methods like micro grinding, micro casting and chemical etching, micro-electrical discharge machining (micro-EDM), micro-electro chemical machining, micro-CNC, abrasive jet machining, ultrasonic machining, laser beam machining method, Vibromechanical texturing method are commonly adopted. A. Greco et al. [2] used vibromechanical texturing (VMT) in which a controlled vibratory motion of the tool was used to cut micro-sized dimples into the surface of the work piece. J. Choo et al. [3] utilizes Nano imprint lithography (NIL) in producing textures on the surface of ultra-high molecular weight polyethylene (UHMWPE) to efficiently improve the tribological properties of the polymer material. In cutting of complex profiles and drilling holes in wide range of work piece material laser beam machining becomes a powerful method and it has good beam quality, better efficiency, excellent reliability characteristics, and high average beam power [4]. Chemical etching and abrasive machining method has been used to create undulated or modulated patterns that surface texture act as traps for wear debris of oxide [5]. Vibro-rolling technique was prepared by Schneider Y. et al. [6] to produce shallow grooves by plastic deformation using a hard indenter on metallic channels. In the area of hydrodynamic lubrication of textured steel surfaces under reciprocating sliding conditions, Costa et al. [7] investigated the effect of surface texturing on lubricant film thickness for the reciprocating sliding motion of patterned plane steel surfaces against cylindrical counter bodies under hydrodynamic action. A micro-dimple surface texture contributed significant role in improving tribological characteristics and lifespan of mechanical components. G. Ryk et al. [8] experimented to evaluate the effect of laser surface texturing in the form of micro dimples in reciprocating automotive components. The effect of surface texturing under starved lubrication conditions was presented for the plane surfaces configuration. It was shown that dimples act as lubricant reservoirs, when lubricant film is broken down, back-up lubricants was supplied. Laser surface texturing (LST) by dimpling enhanced the mixed, hydrodynamic, and hydrostatic lubrication of conformal sliding components under a point ball-on-flat contact configuration. In LST mechanical seals and thrust bearings there were improvements in high load-carrying capacity, high wear resistance, and low friction coefficients [9]. E. Willis et al. [10] investigated the effect of honing morphologies on cylinder bores of internal combustion engines. These micro-grooves develop the lubrication regimes between the cylinder walls and the piston ring. The effect of elastomer surface texturing in soft elastohydrodynamic lubrication was modelled by A. Shinkarenko et al., [11]. In the presence of viscous lubricant, the model of an elastomer with spherical micro-dimples slides at a constant velocity with respect to a rigid and smooth counterpart. In full and partial texturing of the elastomer surface, both problems are solved simultaneously i.e. hydrodynamic lubrication and elasticity. Tomanik et al. [12] developed a one computer dimensional model to simulate surface texture effects on cylinder bore, top and oil control rings of engine. It has been observed that micro-dimples on the bore and rings were able to generate significant hydrodynamic effect to reduce friction and wear. A significant result was observed when the microdimples were on the oil control rings surfaces. F. Meng et al. [13] studied effect of rectangle shape dimples with flat bottom on the friction of parallel surfaces at various sliding conditions based on lubrication equations. The elastic deformation of rough surfaces is evaluated using continuous convolution fast Fourier transform. X. Zhang et al. [14] used sandwich-like electrochemical micromachining to produce micro-dimples. The experimental results show that a porous metal cathode can remove gas bubbles and some nonconductive insoluble electrolytic products, leading to deep microdimples. Ultrasonic vibration was applied by P. Liew et al. [15] to dielectric fluid by a probe-type vibrator to assist microEDM of deep micro-holes in ceramic materials. Ultrasonic vibration influences two major effects one is stirring effect contributing in uniform distribution the carbon nano-fibers and other is the cloud cavitation bubbles which flush out the debris. Ze Wu et al. [16] investigated tribological properties of dimple-textured titanium alloys under high-speed dry sliding contact. The dimpledistance has a remarkable effect on both the average friction coefficients and the wear rates of titanium surfaces. Yang Fu, et al. [17] studied the influence of conductive grease (CG) on the tribological properties of carbon brushes and the collection effect of surface texture on carbon powder. Studies have shown that a conductive lubricating film is formed on the surface of the carbon brush, and a large amount of carbon powder is detected in the surface texture holes of the carbon brush, indicating that surface texture can be used as a collector for carbon powder. Jiang et al. [18] fabricated micro-grooves on GCr15 steel disc and filled by epoxy resin composites, formed hybrid laser surface texture and investigated tribological properties of textured disc sliding against ceramic ball. It was found that this hybrid laser surface texture could form a transfer layer on the contact surface, which contribute to the friction and wear reduction of tribo-pairs under dry friction condition. Zhang H. et al. [19] studied the tribological performance of journal bearings by optimizing the coverage area of circular micro-textures in divergent region of the sleeve and proposed a numerical model is to calculate the friction coefficient and bearing load of textured journal bearings. Ming et al. [20] studied the effect of nitriding/surface texturing combined treatment on vacuum tribological properties of titanium. It has been observed that nitriding/surface texturing combined treatment not only enhances the wear resistance but also has a lower friction coefficient than the nitriding treatment. The high hardness of nitrided layer and the function of micro-trap 
for wear debris of surface texture results in the excellent tribological properties. Huang et al. [21] constructed the texture of the circular pits with different areal densities on the nickel surface by laser surface texturing. The coefficient of friction of the circular pit under the water-lubricated friction condition was kept at about 0.17 , while the untreated metal nickel under the same conditions exceeds 0.65 . The circular pit texture improves the frictional properties of the nickel surface. In the present study, surface texturing by micro dimple formation on EN-31 alloys steel was performed using micro drilling$\mathrm{CNC}$ and micro-EDM processes and textured samples were tested for wear analysis on DUCOM pin-on-reciprocating plate tribometer under wet condition. Micro-EDM method provides superior frictional characteristics and hence that can enhance mixed film hydrodynamic lubrication between plate and pin which leads to decrease in wear loss.

\section{MATERIALS AND EXPERIMENTAL METHODS}

$\mathrm{I}$ $\mathrm{n}$ the present work, the tribological characteristic of EN-31 alloy steel plate of size $40 \times 40 \times 6 \mathrm{~mm}^{3}$ under wet conditions was investigated. The normal loading was applied through an EN-8 steel pin on EN-31 alloy steel plate by using pin-on-plate reciprocating tribometer.

The chemical compositions and mechanical properties of EN-8 steel pin and EN-31 alloy steel plate are shown in Tab. 1 to Tab. 4.

\begin{tabular}{ccccc}
\hline $\mathrm{C} \%$ & $\mathrm{Si} \%$ & $\mathrm{Mn} \%$ & $\mathrm{P} \%$ & $\mathrm{~S} \%$ \\
$0.36-0.44$ & $0.10-0.40$ & $0.60-1.00$ & 0.05 & 0.05 \\
\hline
\end{tabular}

Table 1: Chemical compositions of EN-8 steel.

\begin{tabular}{lccc}
\hline YS $[\mathrm{MPa}]$ & UTS $[\mathrm{MPa}]$ & Hardness & $\begin{array}{c}\text { Heat } \\
\text { Treatment }\end{array}$ \\
$280 \mathrm{MPa}$ & $550 \mathrm{MPa}$ & $152-207$ & Normalizing \\
\hline
\end{tabular}

Table 2 Mechanical properties of EN-8 steel.

\begin{tabular}{ccccc}
\hline $\mathrm{C} \%$ & $\mathrm{Si} \%$ & $\mathrm{Mn} \%$ & $\mathrm{Cr} \%$ & $\mathrm{~S} \%$ \\
$0.95-1.10$ & $0.10-0.35$ & $0.40-0.70$ & $1.20-1.60$ & 0.05 \\
\hline
\end{tabular}

Table 3: Chemical compositions of EN-31 alloy steel.

\begin{tabular}{ccccc}
\hline $\begin{array}{c}\text { Bulk } \\
\text { Modulus }\end{array}$ & $\begin{array}{c}\text { Elastic } \\
\text { Modulus }\end{array}$ & $\begin{array}{c}\text { Shear } \\
\text { Modulus }\end{array}$ & $\begin{array}{c}\text { Hardness, } \\
\text { Knoop }\end{array}$ & Poisson's Ratio \\
$140 \mathrm{GPa}$ & $190-210 \mathrm{GPa}$ & $80 \mathrm{GPa}$ & $706-739$ & $0.27-0.30$ \\
\hline
\end{tabular}

Table 4: Mechanical properties of EN-31 alloy steel.

Initially pin on plate tribo-analysis was carried out for un-textured EN-31 alloy steel plate by using two different lubricants ISO-68 and ISO-220 oil under the following operating conditions:

Normal loading $=20$ to $100 \mathrm{~N}$; Temperature $=40^{\circ} \mathrm{C}$; Humidity $=37 \mathrm{RH}$; Stroke length $=10 \mathrm{~mm}$; Frequency $=12 \mathrm{~Hz}$. The property of lubricants used in experiments is shown in Tab. 5.

Then after a surface texturing i.e. micro-dimples are generated by using two machining processes i.e. micro-EDM and micro-drilling CNC. Fig. 1(a) shows micro-dimples on the surface of the EN-31 specimen which are uniformly arranged in a rectangular array.

The surface texture density $\left(\mathrm{T}_{d}\right)$ is calculated by using the following equation; 


$$
T_{d}=\frac{\text { Area of the dimple }}{\text { Area of the micro dimple unit }}=\frac{A_{d}}{A_{t}}(\%)
$$

If, $\mathrm{d}=$ diameter of the dimple; $\mathrm{k}$ and $l=$ sides length of the micro-dimple unit or spacing between dimples,

Then, $\mathrm{A}_{d}=\pi \mathrm{d}^{2 / 4} ;$ and $\mathrm{A}_{t}=\mathrm{k} \times l$;

$$
\therefore T_{d}=\frac{\pi d^{2}}{4 \times k \times l}(\%)
$$

The dimple parameters of the textured surface for friction-wear test analysis are shown in Tabs. 6.

\begin{tabular}{lcccccc}
\hline Lubricant & $\begin{array}{r}\text { Viscosity at } \\
40^{\circ} \mathrm{C} \\
(\mathrm{cSt})\end{array}$ & $\begin{array}{c}\text { Viscosity at } \\
100^{\circ} \mathrm{C} \\
(\mathrm{cSt})\end{array}$ & $\begin{array}{c}\text { Density } \\
\text { at } 15.6^{\circ} \mathrm{C} \\
\left(\mathrm{kg} / \mathrm{m}^{3}\right)\end{array}$ & $\begin{array}{c}\text { Viscosity } \\
\text { Index }\end{array}$ & $\begin{array}{c}\text { Flash } \\
\text { Point }\left({ }^{\circ} \mathrm{C}\right)\end{array}$ & $\begin{array}{c}\text { Pour } \\
\text { Point }\left({ }^{\circ} \mathrm{C}\right)\end{array}$ \\
ISO 68 & 68.0 & 10.2 & $0.88 \times 10^{3}$ & 135 & 204 & -40 \\
ISO 220 & 220.0 & 30.4 & $0.86 \times 10^{3}$ & 180 & 233 & -39 \\
\hline
\end{tabular}

Table 5: Properties of lubricant.

\begin{tabular}{lccccc}
\hline $\begin{array}{l}\text { Parameters } \rightarrow \\
\text { Test } \downarrow\end{array}$ & $\begin{array}{c}\text { Dimples } \\
\text { Diameter } \\
(\mathrm{d}) \mu \mathrm{m}\end{array}$ & $\begin{array}{c}\text { Dimple } \\
\text { Depth } \\
(\mathrm{h}) \mu \mathrm{m}\end{array}$ & $\begin{array}{c}\text { Side } \\
\text { Length } \\
(\mathrm{k}) \mu \mathrm{m}\end{array}$ & $\begin{array}{c}\text { Side } \\
\text { Length } \\
(l) \mu \mathrm{m}\end{array}$ & $\begin{array}{c}\text { Texture } \\
\text { Density } \\
(\mathrm{T} d) \%\end{array}$ \\
1. & 500 & 10 & 1800 & 2200 & 5 \\
2. & 700 & 10 & 1800 & 2200 & 10 \\
\hline
\end{tabular}

Table 6: Dimple parameters of textured surface.

The electro discharge machining (EDM) process plays a significant role in research of micro machining especially in the machining of micro-dimple textures. The micro-dimples were performed on the Elektra EMS-5535 as shown in Fig. 1(b). In EDM process, copper electrode of diameter $1.4 \mathrm{~mm}$ was used for the fabrication of micro-dimple texture on EN-31 alloy steel plate. EDM is an electro-thermal non-traditional machining process, where electrical energy is used to produce electrical spark and removal of material mostly arises due to current dynamism of the spark.

The process parameters used for the fabrication of micro-dimple through EDM machine on EN-31 alloy steel are as follows:

Working voltage $(\mathrm{V})=120$ - 130V; Maximum current $(\mathrm{I})=5 \mathrm{Amp}$; Pulse on time $(\mathrm{T})=5 \mu \mathrm{s}$; Gap between the workpiece and the tool $(\delta)=5-50 \mu \mathrm{m}$; Polarity $=$ Straight polarity Tool $(-\mathrm{ve})$; Dielectric medium= EDM oil; Electrode material $=$ Copper; External flushing through spark gap.

Vertical Machining, also known as milling, relies on rotary cutters to remove metal from a work piece. Vertical machining occurs on a vertical machining centre (VMC), which employs a spindle with a vertical orientation. With a vertically oriented spindle, tools stick straight down from the tool holder, and often cut across the top of a work piece.

Fig. 2 shows the experimental setup to perform texturing experiments using ball end mill tool in CNC machine. Detailed view of micro-dimple textures is shown by enlarging the part of experimental setup. The cutting parameters used to fabricate the texture through CNC machine are as follows: feed rate $=150 \mathrm{~mm} / \mathrm{rev}$, spindle speed $=5500 \mathrm{rpm}$ and depth $=10 \mu \mathrm{m}$.

After preparation of micro-dimples on EN-31 plate, these textured surfaces were tested for friction - wear analysis on Linear Reciprocating Tribometer Setup as shown in Fig. 3. The test parameter being used for friction-wear analysis are shown in Tab. 7. 


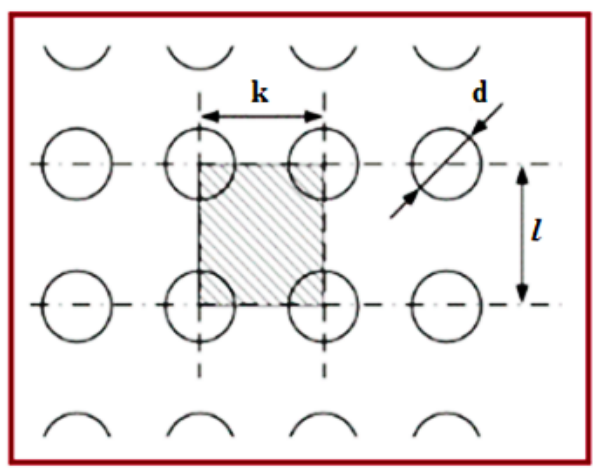

(a)

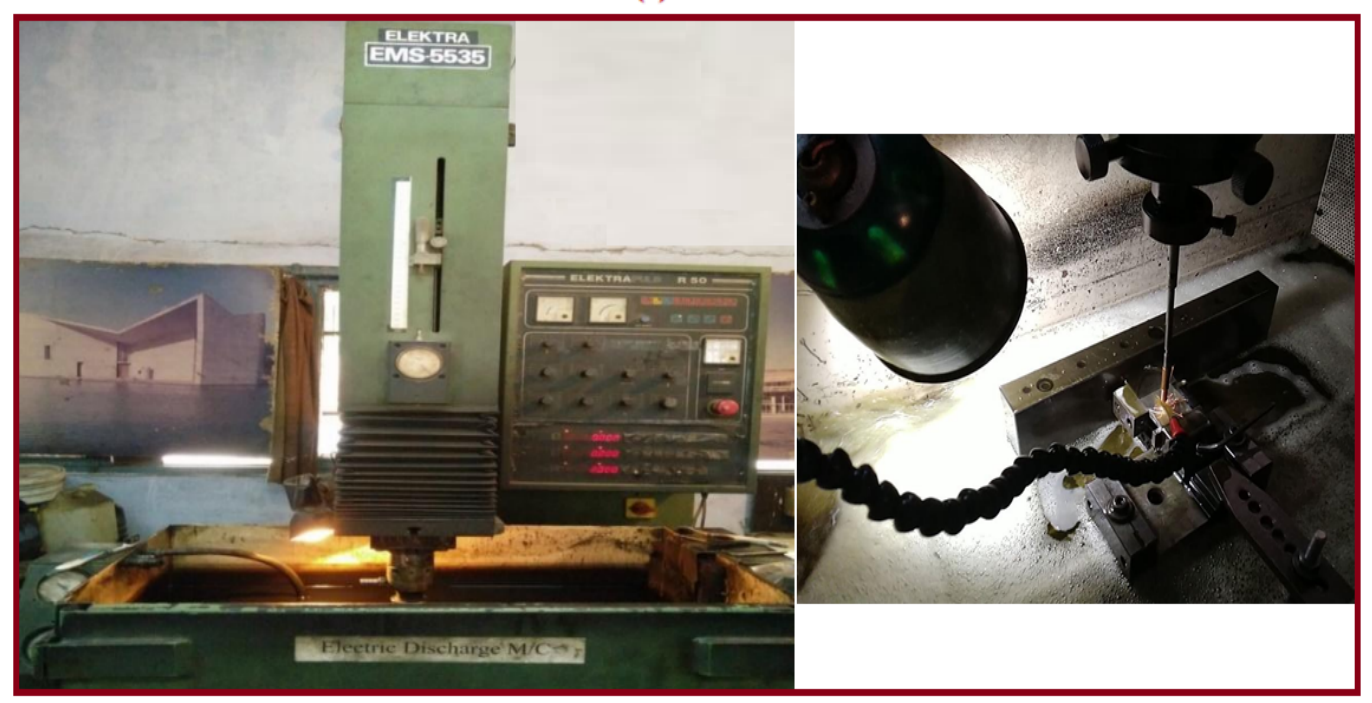

(b)

Figure 1: (a) Micro-dimple array; (b) EDM Machine- Elektra EMS-5535.

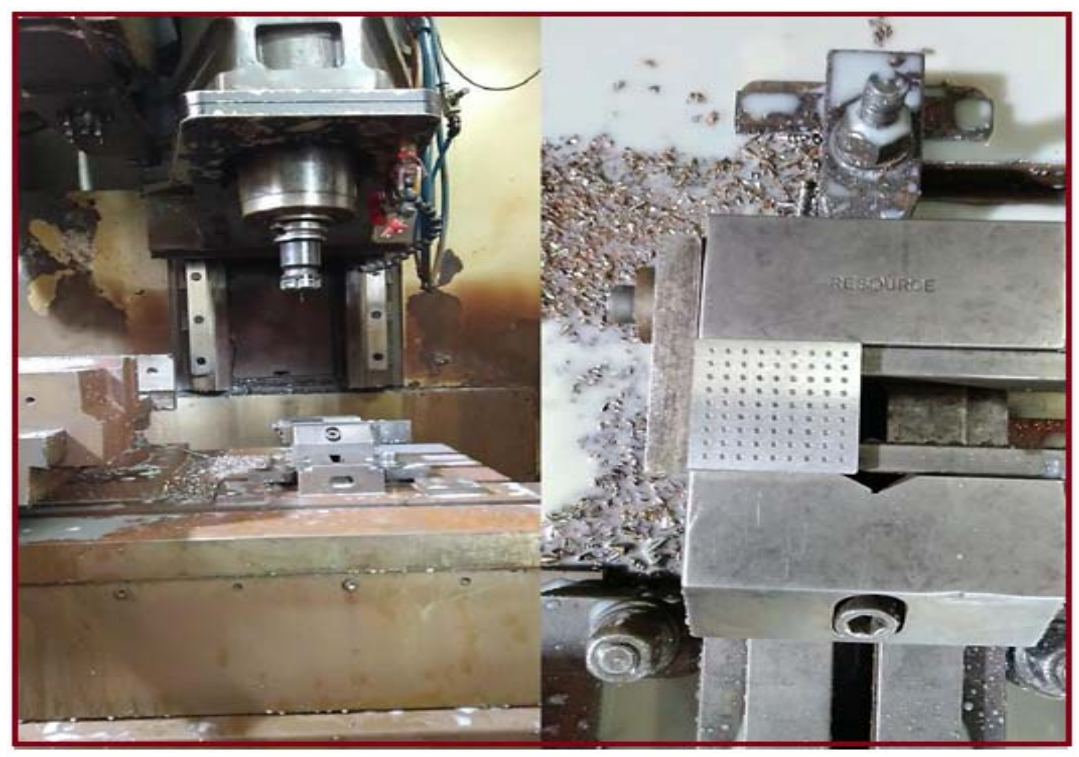

Figure 2: VMC Machine Jyoti PX-20. 


\begin{tabular}{lc}
\hline Normal Load & 60 to $120 \mathrm{~N}$ \\
Temperature & $40^{\circ} \mathrm{C}$ \\
\hline Stroke length & $15 \mathrm{~mm}$ \\
\hline Frequency & $10 \mathrm{~Hz}$ \\
\hline Oil Quantity & $20 \mathrm{ml}$ \\
\hline Test Duration & 20 minutes \\
\hline Lubricant & Slide-way oil ISO 68 and \\
Texture Density & $5 \%$ and $10 \%$ \\
\hline
\end{tabular}

Table 7: Test parameter for friction-wear analysis.

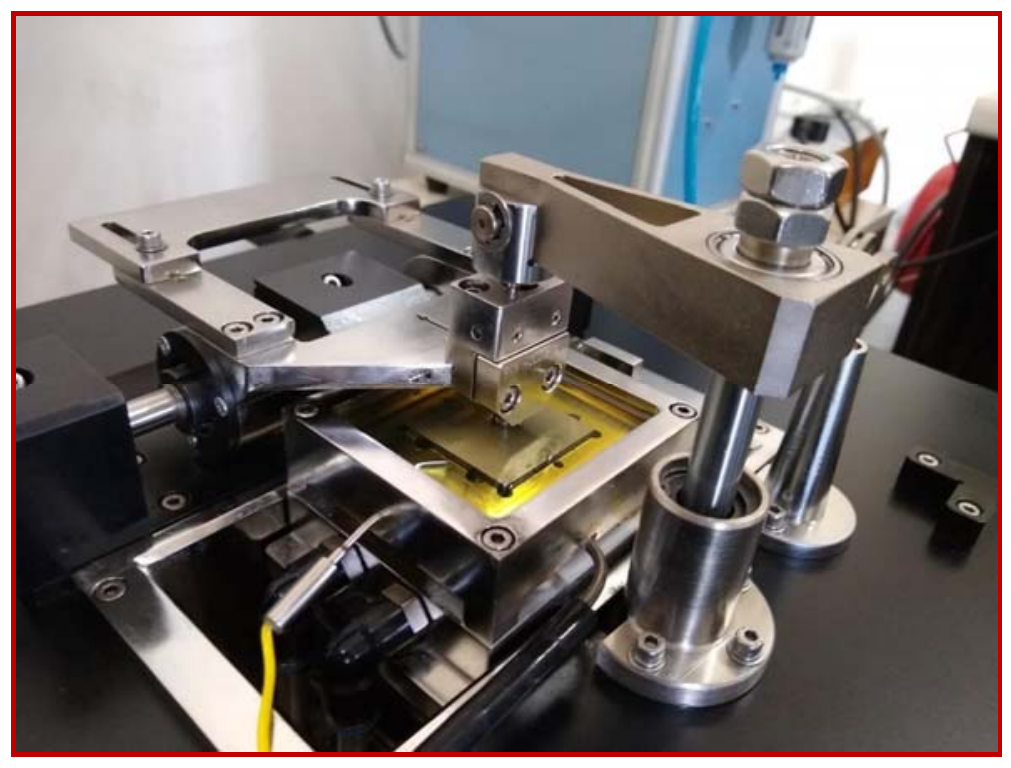

Figure 3: Linear reciprocating tribometer.

\section{RESULTS AND DISCUSSIONS}

\section{Effect of Lubricant on friction and wear}

$\mathrm{F}$

rom Fig. 4 and Fig. 5, it is observed that the average frictional force and co-efficient of friction experienced by pin on plate is lesser in case of ISO-68 oil. The wear loss is more in ISO-220 oil with respect to ISO-68 oil as shown in Fig. 6. These observations indicate that the oil film of ISO-220 lubricant does not remain stable and it breaks during rubbing action which leads to poor friction characteristics as compared to ISO-68. Also during test operated under ISO-220 oil, unpleasant noise was noticed that may be due to boundary lubrication between pin and plate.

It is noticeable that the friction force and the COF have reduced for applied loading in ISO-68 oil. Therefore it can be predicted that the semi-finished surface of the specimen acts as a surface texture itself. It is clear from the above results that ISO-68 proves itself to be better lubricant as compared to ISO-220 for relative sliding motion of EN-8 pin and EN31 plate. Based on the above results the friction-wear test is carried out on textured samples at varying load conditions under slide-way ISO-68 oil. 


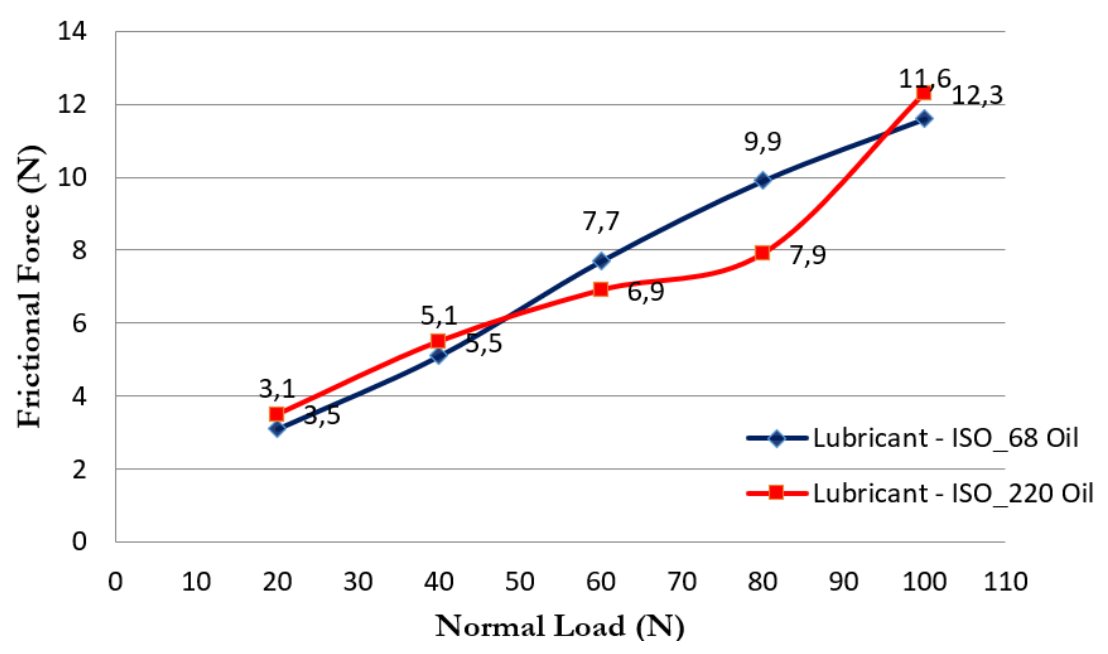

Figure 4: Frictional Force with normal load under different lubricant.

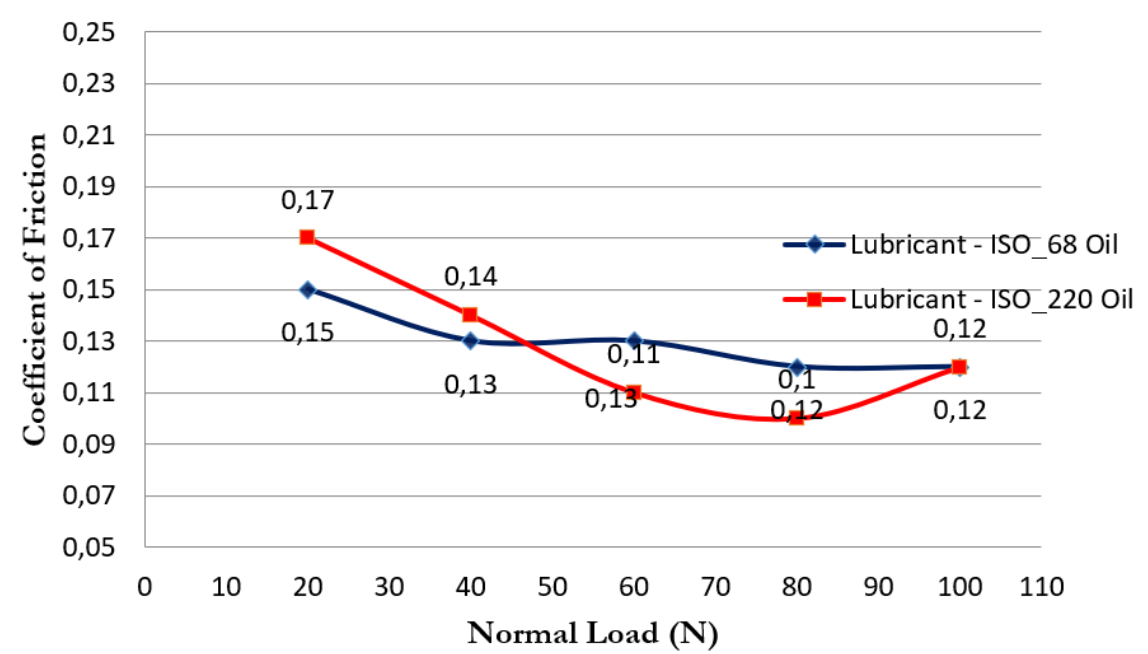

Figure 5: Variation of coefficient of friction with normal load under different lubricant.

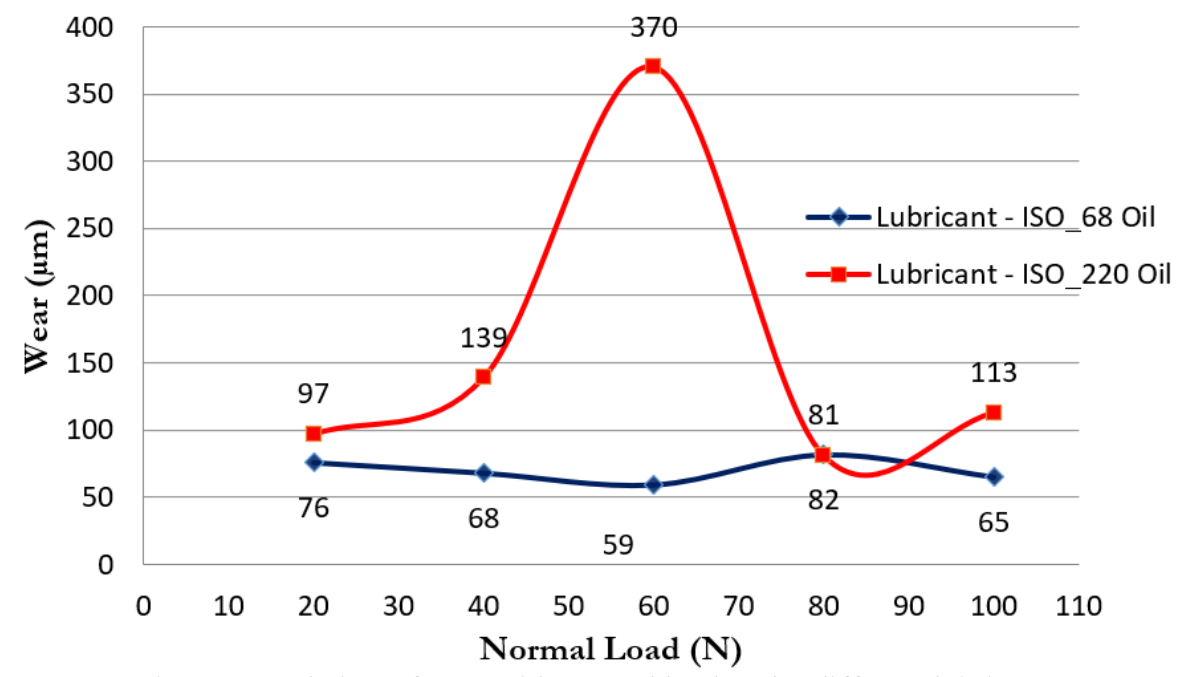

Figure 6: Variation of wear with normal load under different lubricant. 


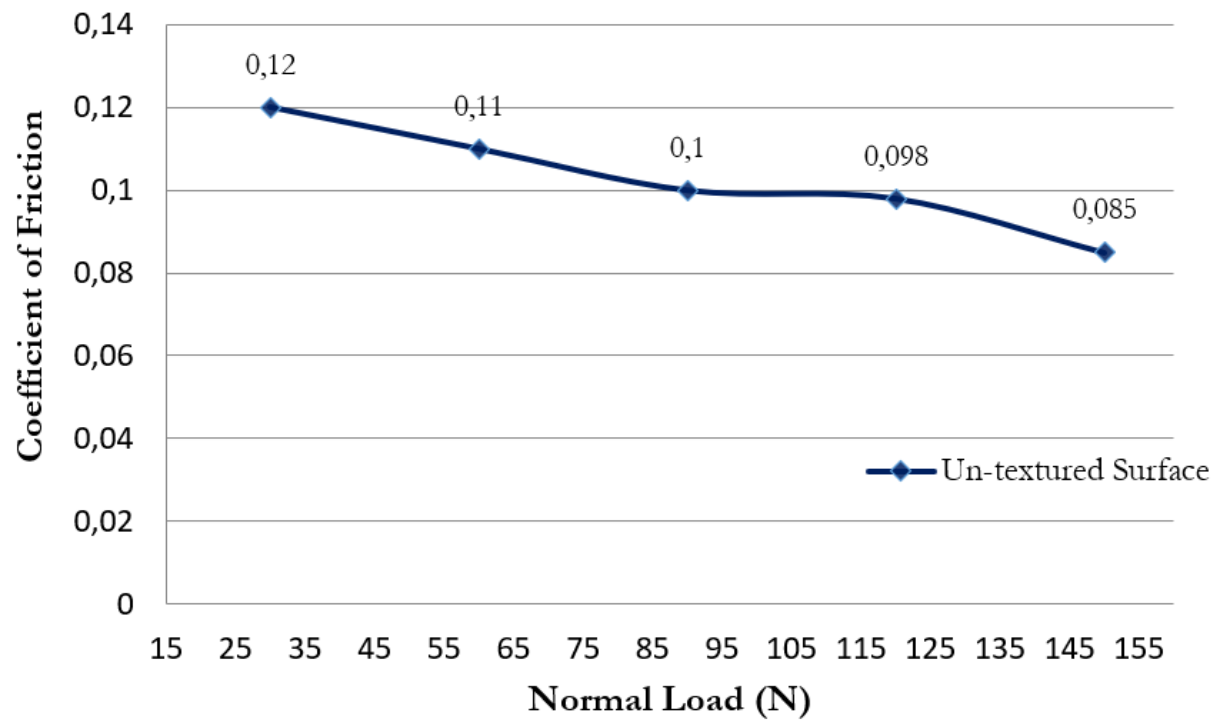

Figure 7: Variation in coefficient of friction with normal load in wet condition.

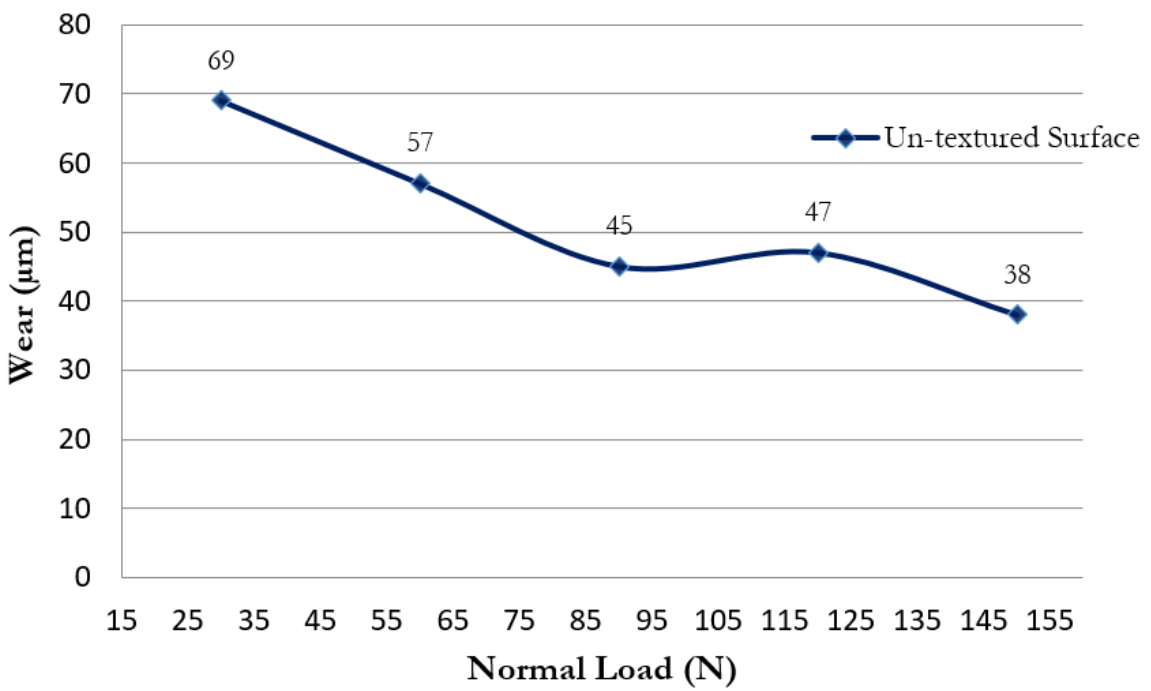

Figure 8: Variation in wear with normal load in wet condition.

Fig. 7 represents the effect of normal load on coefficient of friction operated under wet condition. In this, the test was performed on un-textured plate at temperature of $40^{\circ} \mathrm{C}$ by keeping constant frequency of $10 \mathrm{~Hz}$ and increasing normal load from $30 \mathrm{~N}$ to $120 \mathrm{~N}$. The test was carried out in slide-way oil ISO-68 for 20 minutes time duration. On increasing normal load, coefficient of friction decreases and its minimum value obtained during test is 0.085 and wear also decreases up to $38 \mu \mathrm{m}$ on increasing normal load as shown in Fig. 8.

\section{Effect of surface texture density on friction and wear}

Figs. 9-10 shows effect of texture densities on friction coefficients of the pin on plate with respect to normal load for both the methods of texturing respectively. During the friction-wear test on tribometer, normal loads of $30 \mathrm{~N}$ to $120 \mathrm{~N}$ were applied for duration of 20 minutes each time. In initial phase of the experimentation operated under the normal load of $30 \mathrm{~N}$ to $60 \mathrm{~N}$ with $5 \%$ and $10 \%$ texture density, the friction coefficients of the test surfaces observed very high for both methods i.e. micro-EDM as well as micro-drilling CNC. This is because, here the lubricating oil ISO-68 exhibits the colloidal characteristics, which makes it difficult to form a uniform stable oil film on the surface contact of EN-31 alloy steel, which results in a poor lubrication effect. 


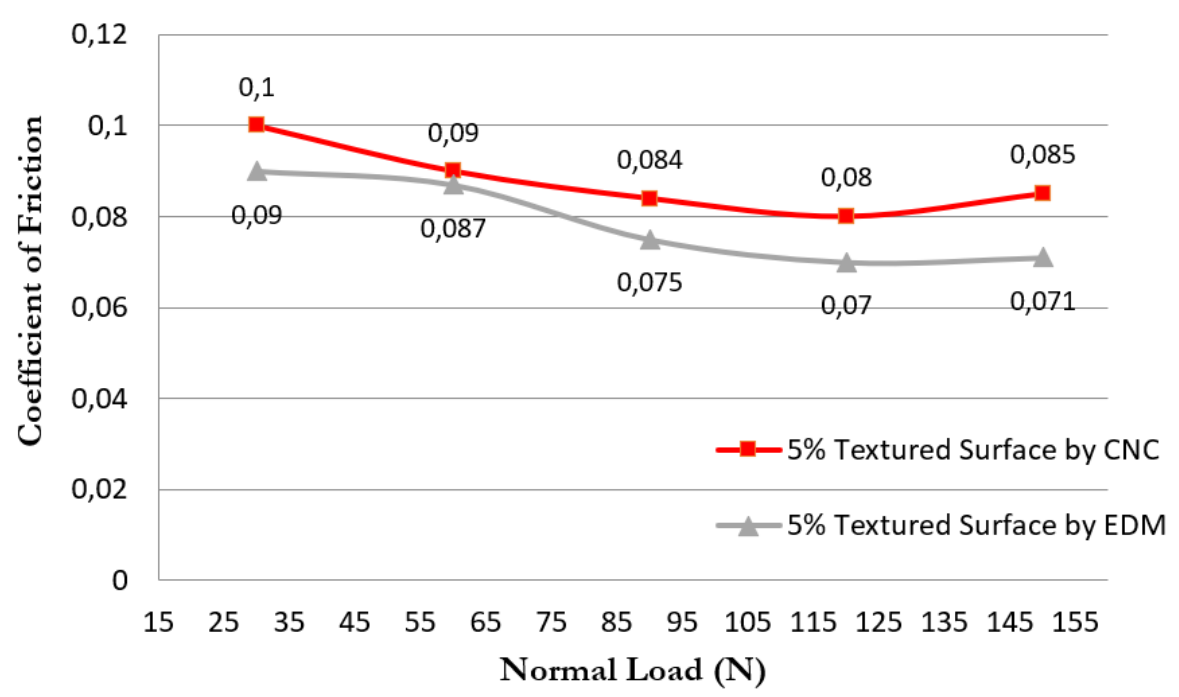

Figure 9: Coefficient of friction with normal load for $5 \%$ texture density in wet condition.

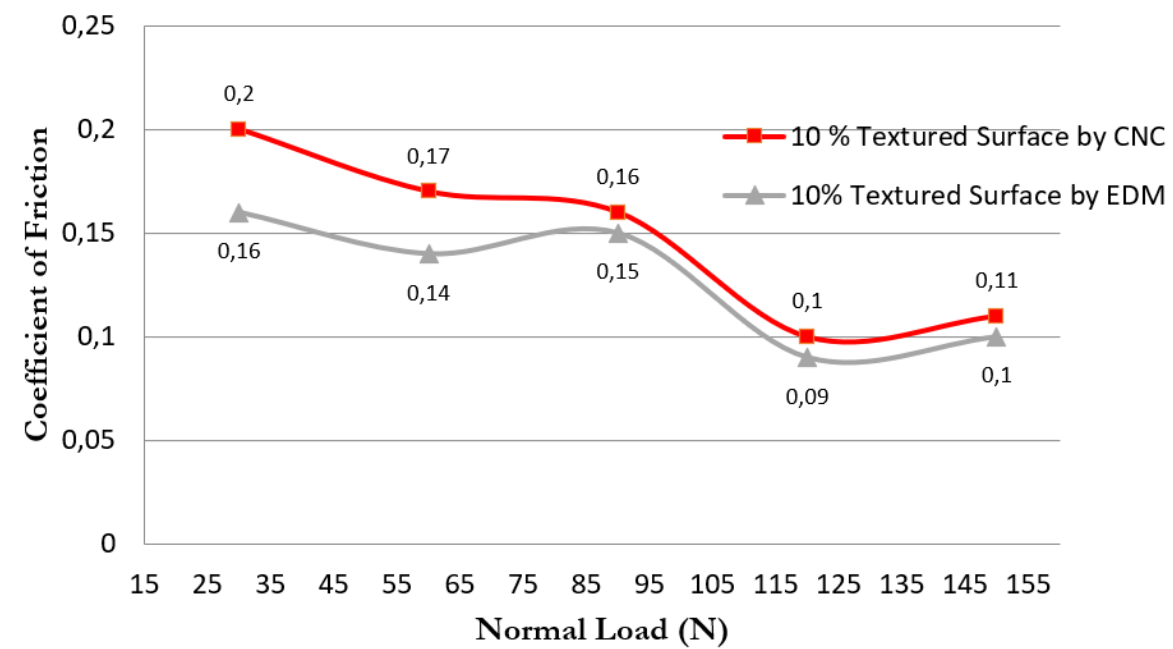

Figure 10: Coefficient of friction with normal load for 10\% texture density in wet condition.

It can be also seen that the friction coefficients of the micro-EDM and micro-drilling CNC specimens are reduced by increasing the normal load ranging from $30 \mathrm{~N}$ to $150 \mathrm{~N}$. In both cases of micro-dimple texturing the friction coefficient of all the specimens was very high under initial loading of 30-60N. From the friction-wear test it is observed that the textured plate with $5 \%$ density has low coefficient of friction in comparison with respect to plate with $10 \%$ density. This signifies that at low contact pressure, the roughness of the surface had a certain effect on the frictional properties of sliding surfaces, as higher texture density led to higher roughness value, and therefore a higher coefficient of friction was more easily found. Later on, as the load on the surfaces increased, the coefficients of friction of the textured surfaces were sharply reduced. This is attributing to the large quantity of oil being constantly released from the micro-dimples into the sliding contact surface. Thus, here the lubricant contributed to achieve a steady lubricating oil film due to the squeezing effect of the load.

Figs. 11-12 shows effect of texture densities on wear loss with respect to normal load for both the methods of texturing respectively. In both the texturing methods the loss of wear decreases with respect to increasing applied normal load. From these figures, it is observed that the textured plate with 5\% density has low wear loss with respect to plate with $10 \%$ density for micro-EDM texturing process.

Fig. 13 shows the optical micro-graph of textured surface with $5 \%$ and $10 \%$ density for friction-wear test. Around the micro-dimple, it can be seen that the heat zone was formed due high energy. The bulges around dimple are little higher 
than plane surface which increases the surface roughness of textured specimens. Average surface roughness measured for $5 \%$ textured and $10 \%$ textured plates are $0.21 \mu \mathrm{m}$, and $0.25 \mu \mathrm{m}$ respectively.

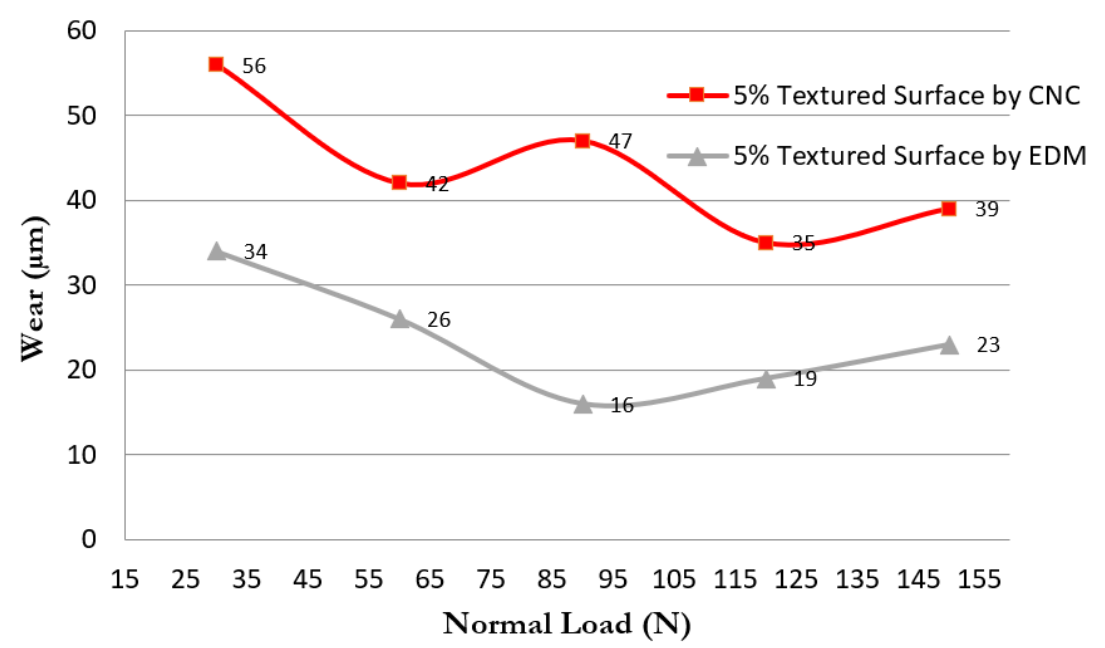

Figure 11: Wear loss with normal load for 5\% texture density in wet condition.

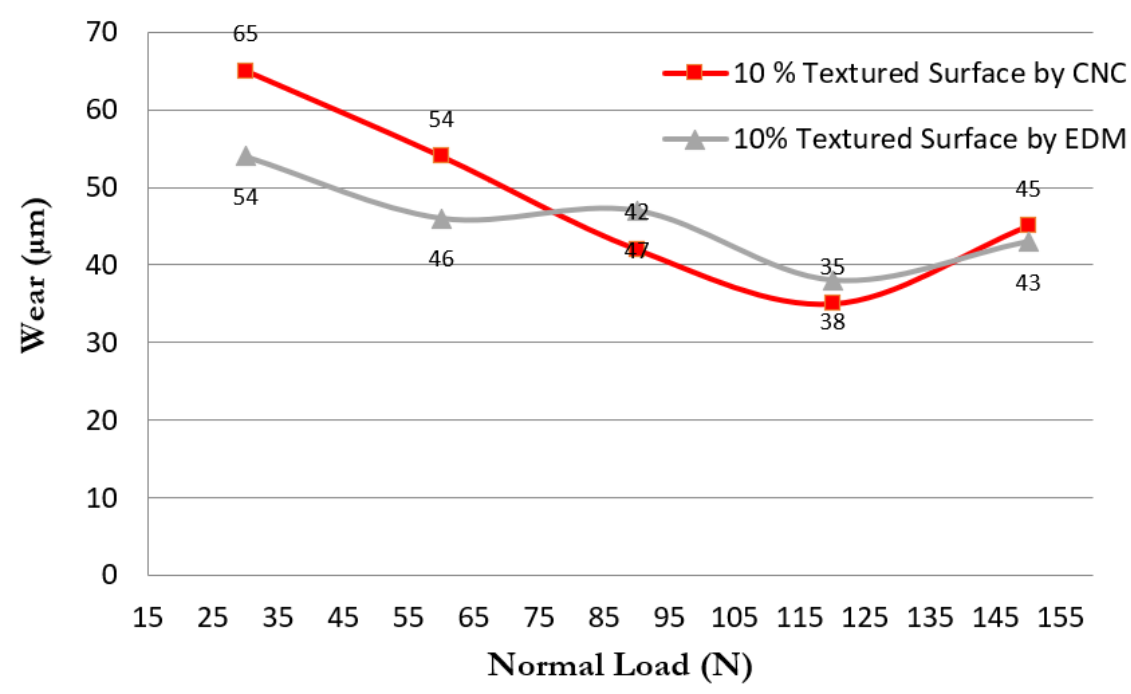

Figure 12: Wear loss with normal load for $10 \%$ texture density in wet condition.

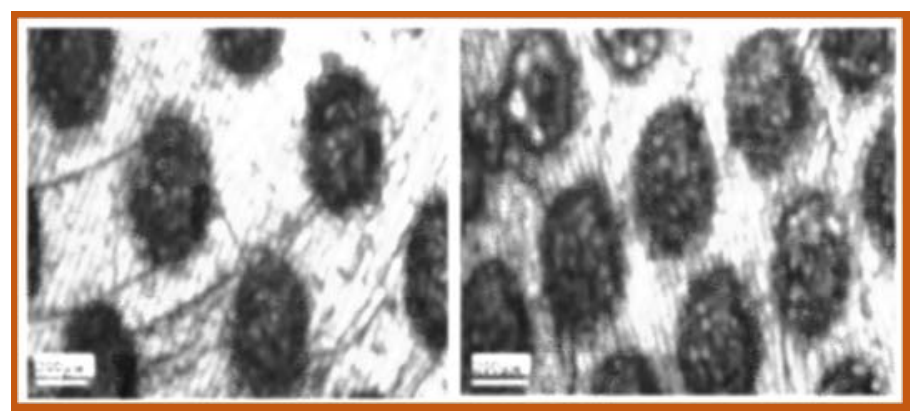

Figure 13: Optical micro-photograph of textured surface (a) 5\% texture density (b) 10\% texture density.

Wear debris analysis

During reciprocating testing, the gathering of wear rubbles is obviously a major factor affecting the wear performance of the textured surfaces. Scanning electron micrographs of the wear tracks helped the tribological analysis of the un-textured 
and textured surface at different load conditions of sliding motion. The SEM of specimen was performed on magnifications of 50X and 100X. SEM micrograph in Fig. 14 shows the worn out surfaces of the un-textured surface i.e. plane surface. Deep surface scratches and material loss could be clearly observed as an abrasive wear during the test. For un-textured surface, it is difficult to reserve debris and lubricant. The debris generated by friction can cause micro-cutting on the un-textured surface and that can lead to abrasive wear.

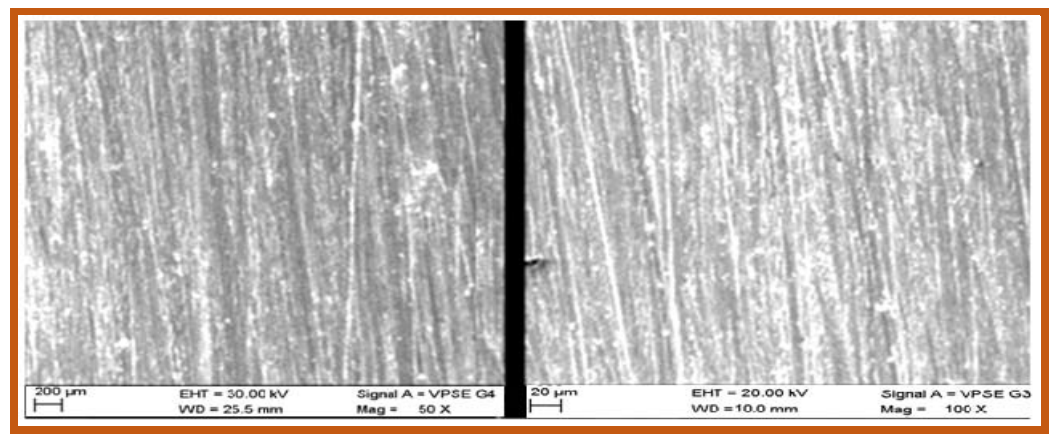

Figure 14: Wear surface of un-textured samples:( a) low (b) high magnification showing fragmentation.

Figs. 15-16 show the SEM micrographs of micro-EDM surfaces having 5\% texture and 10\% texture respectively, which represents the presence of worn surface topography as an abrasive wear. That is similar to that of the un-textured surface but here wear area as well as the width and depth of scratches looks smaller than those on the un-textured surface. These results signify that micro-dimples have an influence on wear resistance. It is observed that in textured plate wear debris and lubricant present between pin and plate filled into circular dimple cavity due to which friction between pin and plate is reduced as compare to un-textured plate and as a result of these, only shallow shape scratches were observed on the wornout surface of textured plate and some original surface topography can still be observed on the plate (Fig. 15).

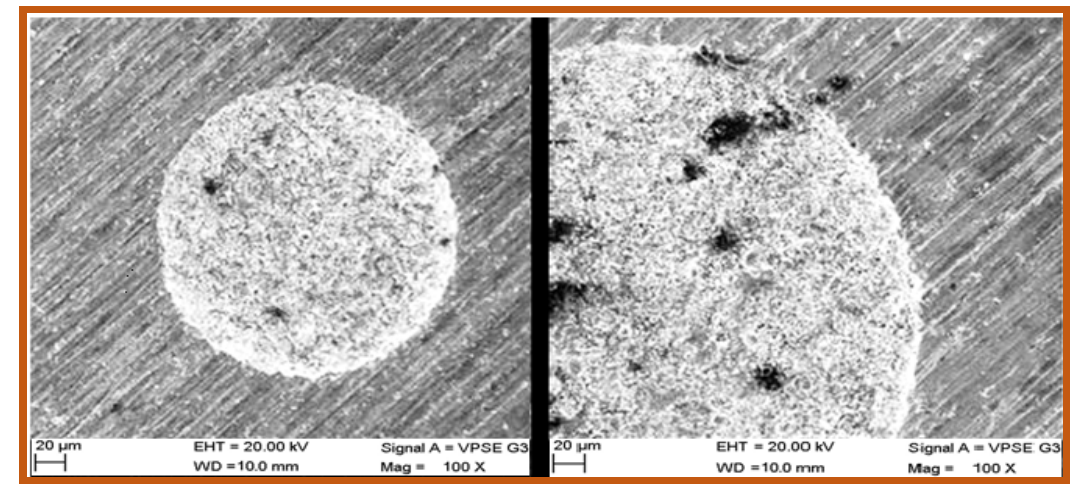

Figure 15: Wear surface of 5\% surface textured samples.

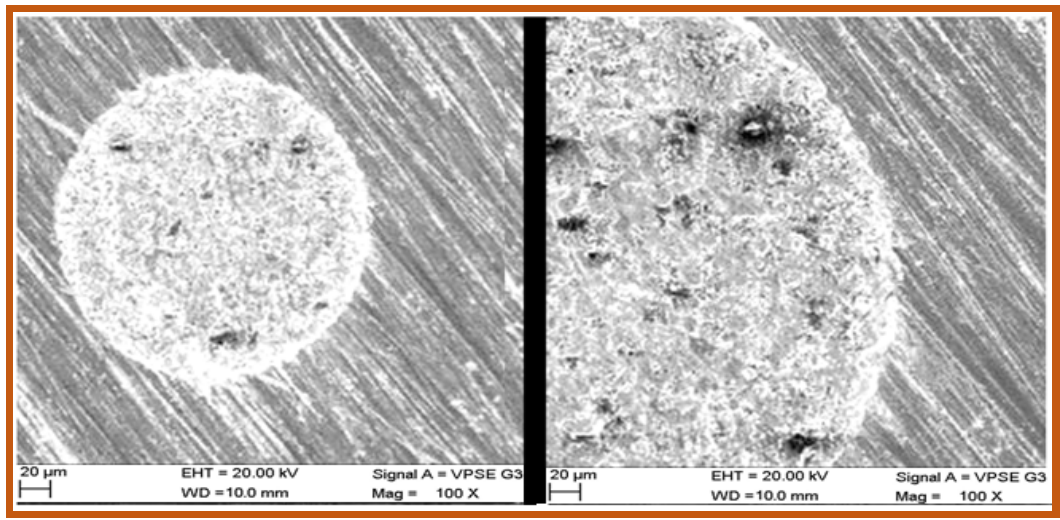

Figure 16: Wear surface of $10 \%$ surface textured density. 


\section{CONCLUSION}

$\mathrm{T}$ he current research work investigated the effect of surface texturing in the sliding surface on tribological characteristics of EN-31 alloy steel under lubricated condition. Two texturing methods, EDM and CNC machining were adopted to fabricate micro-dimples on the contact surface of the plate with different texture densities. The experimentations helped in understanding the tribological characteristics of textured surfaces in wet condition. Based on the experimental results, the conclusions drawn are:

a. The surface texturing leads to better tribological characteristics in terms of friction and wear. The cost of surface texturing can be justified by the increased life of materials.

b. The friction and wear are influenced by the geometry and method of surface texturing. Increase in texture densities leads to rise in friction and wear at a constant texture depth.

c. Experimentally observed that 5\% surface texture exhibited the best friction - wear properties in all conditions as it could supply more lubricant and trap wear debris.

d. Surface texturing by micro-EDM process provides better tribological characteristics with respect to micro-drilling CNC process under ISO-68 oil lubricated condition.

e. Friction reduction by surface texturing may be attributed to the hydrodynamic action, which increases the sliding gap and reduces the possibility of material asperity contact.

\section{REFERENCES}

[1] Bruzzone, A. A. G., Costa, H. L., Lonardo, P. M. and Lucca, D. A. (2008). Advances in engineered surfaces for functional performance, CIRP Annals - Manufacturing Technology, 57, pp. 750-769.

[2] Greco, A., Raphaelson, S., Ehmann, K., Jane Wang, Q., Lin, C. (2009), Surface texturing of tribological interfaces using the vibromechanical texturing method, Journal of Manufacturing Science and Engineering - Transactions of the ASME, 131, pp.1-8.

[3] Kustandi, T.S., Choo. J.H., Low, H.Y. and Sinha S.K. (2010), Texturing of UHMWPE surface via NIL for low friction and wear properties, Journal of Physics D:Applied Physics, 43, pp. 1-6.

[4] Dubey, A.K. and Yadav, V. (2008), Laser beam machining - a review, International Journal of Machine Tools and Manufacture, 48(6), pp. 609-628.

[5] Suh, N.P., M. Mosleh and P.S. Howard (1994), Control of friction, Wear, 175, pp. 151- 158.

[6] Schneider, Y.G. (1984) Formation of surfaces with uniform micro-patterns on precision machine and instrument parts, Precision Engineering, 6, pp. 219-225.

[7] H L Costa, I M Hutchings, (2007). Hydrodynamic lubrication of textured steel surfaces under reciprocating sliding conditions, Tribology international 40, pp. 1227-1238.

[8] G. Ryk, Y. Kligerman, I. Etsion (2002) Experimental investigation of laser surface texturing for reciprocating automotive components", Tribology Transactions, 45, pp. 444-449.

[9] Kovalchenko, A., Ajayi, O., Erdemir, A. (2011), Friction and wear behaviour of laser surface textured surface under lubricated initial point contact", Wear, 271, pp. 1719-1725.

[10] Willis, E. (1995). Surface finish in relation to cylinder liners, Wear, 109, pp. 351-366.

[11] Shinkarenko, A., Kligerman, Y., Etsion, I. (2009). The effect of surface texturing in soft elasto hydrodynamic lubrication, Tribology International, 42, pp. 284-292.

[12] Tomanik, E., Profito, F.J., Zachariadis, D.C. (2013), Modelling the hydrodynamic support of cylinder bore and piston rings with laser textured surfaces, Tribology International, 59, pp. 90-96.

[13] Fanming, M., Rui, Z., Tiffany, D., Cao, J., Jana Wang, Q., Diann, H. and Liu, J. (2010), Study on the effect of dimples on friction of parallel surfaces under different sliding conditions, Applied surface science, 256, pp. 2863-2875.

[14] Zhang, X., Ningsong, Q., Fang, X (2017). Sandwich-like electrochemical micromachining of micro-dimples using a porous metal cathode. Surface and Coatings Technology, 311, pp 357-364.

[15] Liew, P.J., Yan, J., Kuriyagawa, T. (2014). Fabrication of deep micro-holes in reaction-bonded SiC by ultrasonic cavitation assisted micro- EDM. Int J Mach Tools Manuf. 76, pp. 13-20.

[16] Wu, Z., Xing, Y., Huang, P., Liu, L. (2017), Tribological properties of dimple-textured titanium alloys under dry sliding contact, Surface and Coatings Technology, 309, pp. 21-28 
[17] Fu, Y., Qin, H., Xu, X., Zhang, X., Guo, Z. (2021), The effect of surface texture and conductive grease filling on the tribological properties and electrical conductivity of carbon brushes, Tribology International, 153, pp. 106637.

[18] Jiang, S., Li, J., Liu, S., Zhou, N., Yu, A., Deng, Y. (2019), Tribological properties of hybrid surface textured GCr15 steel filled by epoxy resin-based material under dry friction, Surface Topography: Metrology and Properties, 7(2), pp. 25018.

[19] Zhang, H., Hafezi, M., Dong, G., and Liu, Y. (2018), A Design of Coverage Area for Textured Surface of Sliding Journal Bearing Based on Genetic Algorithm. ASME. Journal of Tribology, 140(6), pp. 61702.

[20] Wang, M.-Z., Kang, J.-J., Yue, W., Fu, Z.-Q., Zhu, L.-N., She, D.-S., Wang, C.-B. (2019), Effects of combined treatment of plasma nitriding and laser surface texturing on vacuum tribological behaviour of titanium alloy, Materials Research Express, 6(6), pp. 66511.

[21] Huang, J., Zhang, L., Wei, S., Yang, Y., Yang, S., Shen, Z. (2019), Fabrication of the laser textured nickel surface and its tribological property under the water lubrication, AIP Advances 9-11, pp.119901. 